\title{
In vitro Anti-inflammatory Evaluation of 6-Thioguanine and 6-Hydroxy-2-Mercaptopurine as A Potential Treatment for Rheumatoid Arthritis
}

\author{
Nurul Syuhada Nordin ${ }^{1}$, Yong Yoke Keong ${ }^{2}$, Siti Farah Md Tohid ${ }^{1}$, \\ Zetty Nadia Md Zain ${ }^{3}$, Muhammad Nazrul Hakim ${ }^{1,4 *}$ \\ ${ }^{1}$ Department of Biomedical Sciences, Faculty of Medicine and Health Sciences, Universiti Putra Malaysia, 43400 UPM Serdang, Selangor, Malaysia \\ ${ }^{2}$ Department of Human Anatomy, Faculty of Medicine and Health Sciences, Universiti Putra Malaysia, 43400 UPM Serdang, Selangor, Malaysia \\ ${ }^{3}$ Faculty of Medicine and Health Sciences, Universiti Sains Islam Malaysia, 71800 Nilai, Negeri Sembilan, Malaysia \\ ${ }^{4}$ Institute of Bioscience, Universiti Putra Malaysia, 43400 UPM Serdang, Selangor, Malaysia \\ *Corresponding author. E-mail: nazrulh@upm.edu.my
}

Received date: Jul 12, 2021; Revised date: Oct 23, 2021; Accepted date: Oct 26, 2021

\section{Abstract}

B ACKGROUND: Eventhough 6-Mercaptopurine act as a major drug for rheumatoid arthritis (RA) treatment, however, its toxicity become a limitation. Therefore, this current study investigated whether 6-hydroxy-2-mercaptopurine (6H2MP) and 6-thioguanine (6TG) compounds are purine nucleoside analogues as a potential treatment of RA. The objective was to evaluate the therapeutics effects, especially the anti-inflammatory potential of 6H2MP and 6TG in the lipopolysaccharides (LPS)-induced RAW264.7 cells and phorbol myristate acetate (PMA)-induced HIG-82 cells.

METHODS: Macrophage cells (RAW264.7) and rabbit synoviocytes (HIG-82) cells were induced using LPS and PMA to evaluate the anti-inflammatory potential of $6 \mathrm{H} 2 \mathrm{MP}$ and 6TG. The cytotoxicity assessment was done by using MTT assay, while enzyme-linked immunosorbent assay (ELISA) was used to determine the anti-inflammatory potential, including tumour necrosis factor (TNF- $\alpha$ ), interleukins (IL-1 $\beta$, and IL-6).
RESULTS: Upon LPS-induced, RAW 264.7 macrophages demonstrated that $6 \mathrm{H} 2 \mathrm{MP}$ and 6TG could suppress the production of nitric oxide (NO) in vitro. The half-maximal inhibitory concentration $\left(\mathrm{IC}_{50}\right)$ value of $6 \mathrm{TG}$ and $6 \mathrm{H} 2 \mathrm{MP}$ were 10.73 and 13.31, respectively. Further studied in PMA-induced HIG-82 synovial fibroblast cells showed that $6 \mathrm{H} 2 \mathrm{MP}$ and $6 \mathrm{TG}$ also suppressed the release of $\mathrm{NO}$, Prostaglandin E2 (PGE2), and inflammatory cytokines such as TNF- $\alpha$, IL- $1 \beta$ and IL- 6 . The 6 TG is more effective to reduce inflammatory reactions compared to $6 \mathrm{H} 2 \mathrm{MP}$, by the lower dose needed compared to $6 \mathrm{H} 2 \mathrm{MP}$ in all experiments except in PGE2.

CONCLUSION: The inhibition of inflammatory mediators is an important mechanism by which 6TG and 6H2MP may alleviate pain and articular inflammation. These results indicated that $6 \mathrm{H} 2 \mathrm{MP}$ and $6 \mathrm{TG}$ are effective candidates for ameliorating inflammatory-associated complications.

KEYWORDS: anti-inflammatory, HIG-82 cells, RAW264.7 cells, 6-Thioguanine, 6-Hydroxy-2-Mercaptopurine

Indones Biomed J. 2021; 13(4): 383-95

\section{Introduction}

Infection, stress, and injury will cause inflammation. Macrophages play the main role as key modulator and effector cells in immune response as an immediate defence against foreign agents in the initiation, maintenance, and resolution of inflammation. Macrophages will be activated upon inflammatory stimuli and produce mediators that include nitric oxide (NO) and prostaglandin E2 (PGE2). The inflammatory cytokines such as tumor necrosis factor (TNF)- $\alpha$, interleukin (IL)-1 $\beta$, and IL-6 will also be produced. RAW 264.7 macrophages stimulated by lipopolysaccharide (LPS) is the common technique to 
investigate these inflammatory cytokines.(1) RAW 264.7 cells, easily cultured, and phenotypically resemble primary macrophages. For these reasons, they have been used extensively in various macrophage cellular physiology studies. LPS-stimulated RAW 264.7 macrophage is a model for anti-inflammatory drug screening and in the investigation of the signal pathways involved for the proinflammatory cytokines production and enzyme induction. (1) The immortalized rabbit synovial fibroblast HIG82 cells line, which shares numerous characteristics of activated human rheumatoid synovium in the same concentrations, mimics the same conditions as rheumatoid arthritis pathogenesis.(2)

The thiopurines antimetabolites, 6-mercaptopurine (6MP) or PurinetholTM and 6-thioguanine (6TG) or Thioguanine TabloidTM are structural purine analogues act as anti-cytotoxic agent which often used as anticancer drugs and acute leukemia treatment. Commonly administered to patients orally, undergo both intestinal and hepatic metabolism to form thioguanine nucleotides before incorporated into DNA by replacing the endogenous purine guanine. The 6-hydroxy-2-mercaptopurine (6H2MP) is an end product of enzymatic hydroxylation of 2-mercaptopurine (2MP), which is the analogue of 6MP. The active form of $6 \mathrm{TG}$ is closely related to mercaptopurine and similarly inhibits purine metabolism. 6TG currently is used against inflammatory bowel disease as well as several lymphoid tumors such as acute myeloid leukemia (AML), acute lymphoid leukemia (ALL) and chronic myeloid leukemia (CML).(3)

Drugs for the treatment of RA are usually used to control the normal state of body's immune system from further damaging the joints. Intracellular metabolism will either inhibit de novo purine synthesis (DNPS) or incorporate into DNA for drugs that are inactive (pro-drugs) and cause cytotoxicity DNA.(4) Due to its structural similarity to purines, $6 \mathrm{H} 2 \mathrm{MP}$ and $6 \mathrm{TG}$ are able to inhibit DNA synthesis and disrupt the leukocyte proliferation. The broadly T-cell effects allow them to inhibit autoimmune responses (5) occurred in arthritic disease and 6TG is proved to triggers apoptosis in a cancer cell-specific manner (6).

In this study, the ability of these two drugs; 6TG and $6 \mathrm{H} 2 \mathrm{MP}$ to inhibit the inflammatory cytokines and inflammatory mediators were studied separately. The two druges were tested in 2 different groups with various concentrations by using medium cells which are LPSstimulated RAW264.7 cells and PMA-stimulated HIG-82 cells.

\section{Methods}

\section{In Vitro Cell Viability and Anti-inflammatory Testing} RAW 264.7 cells and HIG-82 cells (American Type Culture Collection, Manassas, VA, USA) were used to initially screen and examined the effects of the drugs on apoptotic cell death and their anti-inflammatory properties. These were done via the cell viability test by using 3-(4,5-dimethylthiazol-2-yl)2,5-diphenyl-tetrazolium bromide (MTT) assay and were continued by investigating the NO production by using Griess reagent. In an attempt to know how $6 \mathrm{TG}$ and 6H2MP act as an anti-inflammatory drugs on PMA-induced HIG82 cells, the cytokine secretions (TNF- $\alpha$, IL-1 $\beta$, IL-6) and prostaglandin E2 (PGE2) also were analysed by using commercially available ELISA kits.

\section{The Macrophage RAW264.7 Cell Culture Preparation}

The RAW 264.7 cell line was cultured as manufacturer's instructions in Dulbecco's modified Eagle's medium (DMEM) (Gibco BRL, Grand Island, NY) supplemented with $10 \%$ fetal bovine serum (FBS) (Equitech-Bio Inc., Kerrville, TX, USA) and $1 \%$ penicillin-streptomycin solution at $37^{\circ} \mathrm{C}$ in a $5 \% \mathrm{CO}_{2}$ atmosphere.

In preparations of all experiments, cells were grown until achieved $80-90 \%$ confluency. The cells were scraped out from the flasks and centrifuged at $110 \mathrm{~g}$ at $4^{\circ} \mathrm{C}$ for 10 minutes. The media were discarded by pipetting and cells sediment were suspended with new fresh DMEM containing the same supplements.

A standard trypan blue cell-counting technique was used to determine the cell viability. The cells concentration was adjusted to $2 \times 10^{6}$ cells $/ \mathrm{mL}$ with more than $80 \%$ viability. Fifty $\mu \mathrm{L}$ cells were dispensed into 96 -well plate tissue culture-grade with $1 \times 10^{5}$ cells/well concentration in each well. To attach cells to the well plate surface, the plate was incubated for 2 hours at $37^{\circ} \mathrm{C}$ in $5 \% \mathrm{CO}_{2}$ atmosphere.

\section{Cell Cytotoxicity Assay (MTT) for Non-induced and LPS-induced Macrophage RAW264.7 Cells}

The indicator of cell viability was determined when cell respiration being measured as an indicator by using the mitochondrial-dependent reduction of MTT to formazan. The principle of this assay was the ability of viable cells reducing MTT dye to dark blue from pale yellow colour. To prepare the MTT solution, briefly the MTT was dissolved in phosphate-buffered saline at $5 \mathrm{mg} / \mathrm{mL}$. Next it was filtered using $0.2 \mu \mathrm{M}$ filter to sterilize and remove any insoluble residues before being kept in the place out from sunlight 
exposure. The stock solution of MTT was prepared freshly during the day of experiment. After 2 hours incubation of procedure to attach the cells to the well plate surface, the unattached cells were gently discarded, and the attached cells were then stimulated with Escherichia coli LPS (10 $\mu \mathrm{g} / \mathrm{mL}$ ) (for the experiment with inducer) in the presence or absence of the treatment sample (6TG or 6H2MP). Diclofenac sodium $(185 \mu \mathrm{g})$ has been used as a positive control drug in this study. Cells were then incubated in a humidified $5 \% \mathrm{CO}_{2}$ atmosphere for 24 hours at $37^{\circ} \mathrm{C}$.

After an overnight incubation with the treatment samples, $50 \mu \mathrm{L}$ of the spent media was removed to a new 96-well plate for the next experiment (Griess assay). The stock MTT solution was added to all wells and the plates were incubated at $37^{\circ} \mathrm{C}$ for 4 hours. After 4 hours, the supernatant medium was removed and the remaining dark blue of formazan precipitate was solubilized in $100 \mu \mathrm{L}$ DMSO. The absorbance of each well was measured at $570 \mathrm{~nm}$ on a microplate reader (Infinite M200, Tecan, Port Melbourne, Australia). The cell viability was calculated by the relative reduction of optical density which corresponds with the number of viable cells. Percentage of cell viability $=($ mean absorbance of treated cells $/$ mean absorbance of untreated control) $\times 100$ and analyzed. The $\mathrm{IC}_{50}$ values were determined by the GraphPad Prism software (GraphPad Software, San Diego, CA, USA).

\section{Determination of NO in LPS-induced RAW 264.7 Macrophages Cells}

The NO production in the cell-free culture supernatants was indicated by the accumulation of nitrite. The nitrite levels were determined by Griess reagents.(7) Briefly, $50 \mu \mathrm{L}$ of the supernatant medium was collected from each of the stimulated and treated cell cultures described previously and transferred into a new 96-well plate. These supernatants were mixed with $100 \mu \mathrm{L}$ of Griess reagent in each well and incubated at room temperature for 10 minutes. This was followed by reading the absorbance at $540 \mathrm{~nm}$ by using the microplate reader. The nitrite quantity was determined by comparison with sodium nitrite standard curve. The calculation of the percentage of inhibition was done based on different treatment samples ability to inhibit $\mathrm{NO}_{2}$ below the levels generated by control cells.

\section{Synovial Fibroblast Cells (HIG-82) Cell Culture Preparation}

HIG-82 cells were cultured in Ham's F12 medium and Penicillin-streptomycin solution (Gibco, Grand Island, NY, USA) supplemented with $10 \%$ FBS, $1 \%$ penicillin- streptomycin in a humidified $5 \% \mathrm{CO}_{2}$ at $37^{\circ} \mathrm{C}$. The cells were seeded into $25 \mathrm{~cm}^{2}$ plastic culture flasks with density of $5 \times 10^{5}$ cells/flask. The cells became confluent at 5-7 days later. The confluent cultures were trypsinized and subcultured at a 1:4 split ratio. Cells were grown until achieved (80-90)\% confluency before starts all the experiments. The trypsinized confluent cultures in each flask were centrifuged at $110 \mathrm{~g}$ at $4^{\circ} \mathrm{C}$ for 10 minutes. The medium was discarded, and the cells sediment were suspended with fresh Ham's F-12 nutrient mix medium containing the same supplements.

The cell viability was determined by using the trypan blue cell-counting technique. The cell $\left(2 \times 10^{6}\right.$ cells $\left./ \mathrm{mL}\right)$ with viability more than $80 \%$ were plated into each well of a sterile 96 -well plate. Fifty $\mu \mathrm{L}$ cells were dispensed into each well with $1 \times 10^{4}$ cells/well concentration. The plate was incubated for 24 hours at $37^{\circ} \mathrm{C}$ in $5 \% \mathrm{CO}_{2}$ atmosphere to allow the cells to attach at the well surface.

\section{Cell Cytotoxicity Assay (MTT) for Non-induced and PMA-induced HIG-82 Cells}

The viability assays for activated HIG- 82 cells were performed by 24, 48 and 72 hours of incubation. The indicator of cell viability was determined when cell respiration are measured as an indicator by using the mitochondrial-dependent reduction of MTT to formazan.

Briefly the HIG-82 cells were seeded in 3 different 96well plates for 24 hours of incubation. After finishing the incubation period, the unattached cells were gently discarded. The attached cells were activated with $0.1 \mu \mathrm{g} / \mathrm{mL}$ phorbol myristate acetate (PMA) (Sigma-Aldrich Chemicals, St. Louis, MO, USA) in each well and immediately followed by giving treatments (6TG and 6H2MP). Diclofenac sodium $(185 \mu \mathrm{g} / \mathrm{mL})$ has been used as a reference drug in this study. Cells from each plate were then incubated in a humidified $5 \% \mathrm{CO}_{2}$ atmosphere for 24,48 and 72 hours at $37^{\circ} \mathrm{C}$.

After finishing the incubation period, $50 \mu \mathrm{L}$ of the spent media was removed to a new 96-well plate for the next experiment (Griess assay) and the stock of MTT solution was added to all wells. The plates further were incubated at $37^{\circ} \mathrm{C}$ for 4 hours. The supernatant medium was removed after 4 hours and the remaining dark blue of formazan precipitate was solubilized in $100 \mu \mathrm{L}$ DMSO. The cell viability was determined by absorbance at $570 \mathrm{~nm}$ using a microplate reader.(8)

\section{Determination of NO in PMA-induced HIG-82 Cells}

The NO production or the nitrite levels were determined by Griess reagents and the procedure was same as in the previous section for RAW 264.7 cells.(7) 
Prostaglandin E2 Immunoassay for PMA-induced HIG82 Cells

The concentration of PGE2 in the treated HIG-82 cells were measured by using an ELISA kit (Thermo Scientific, Waltham, MA, USA). The samples were prepared as described in previous section, and the supernatants were collected and used according to the manufacturer's instruction. A standard curve was generated for the PGE2 concentrations estimation. Both negative and positive controls were included in each run.
Inflammatory Cytokines Immunoassays (TNF- $\alpha$, IL-1 and IL-6) for PMA-induced HIG-82 Cells

The effects of the treatment towards inflammatory cytokines production of the treated HIG- 82 cells were determined by using ELISA kits from Thermo Scientific. Briefly the cells cultured as described in previous section; which more than $80 \%$ of viability were plated into sterile 96 -well plate and incubated for 24 hours. The attached cells were activated with $0.1 \mu \mathrm{g} / \mathrm{mL}$ (PMA) followed by 6TG and 6H2MP treatments simultaneously before the next incubation. After
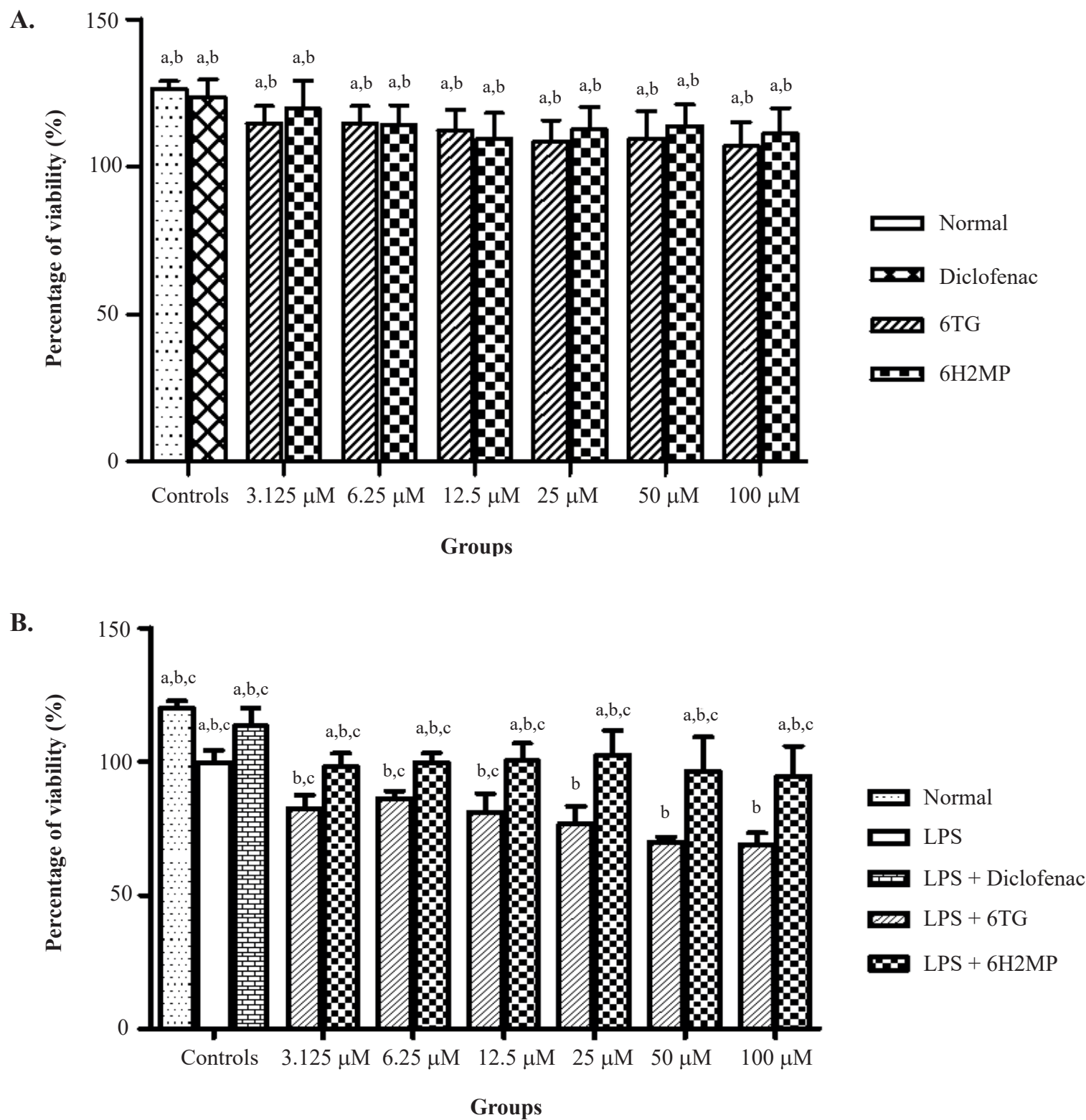

Figure 1. Percentage of viability of non-induced RAW 264.7 cells and LPS-induced RAW 264.7 cells treated with 6TG and 6H2MP for 24 hours. A: Percentage of viability of non-induced RAW 264.7 cells treated with 6TG and 6H2MP for 24 hours; B: The percentage of viability of LPS-induced RAW 264.7 cells treated with 6TG and 6H2MP for 24 hours. Data were analysed using one-way ANOVA followed by Tukey HSD post hoc test and expressed as mean \pm SEM $(n=6)$. Values with different superscript letters differ significantly between groups $(p<0.05)$. 
24 hours, the supernatants of the cell culture medium were collected before performing the assays for TNF- $\alpha$, IL- $1 \beta$, and IL-6 in accordance to the manufacturer's instructions. The cytokines amount was calculated by comparison from the standard curve and the optical density of each well was evaluated by using a microplate reader at $405 \mathrm{~nm}$. All assays were done in duplicate and determined by standard curves from diluted controls.

\section{Statistical Analysis}

The experiments were repeated until 3 data sets (in duplicate) and had been accumulated for each response $(\mathrm{n}=6)$. All results are presented as the mean \pm S.E.M and were analysed by using one-way ANOVA. When ANOVA showed significant differences between groups, Tukey's honestly significant difference (HSD) post hoc test was used to determine the pairs of groups showing statistically significant differences. The significance indicative has been specified into $p$-value less than $0.05(p<0.05)$. All the statistical analysis was carried out by using GraphPad Prism version 5.01 for Windows.

\section{Results}

Cell Viability Percentage on Non-induced and LPSinduced Macrophage RAW264.7 Cells in 24 Hours

In the first experiment (Figure 1A), no-inducer has been added in order to test the toxic effects of the drug directly towards cell without any influence. It was found out that there was no significant suppression of cell viability in all concentration of the drugs-treated group compared to controls group (normal and diclofenac-treated group), indicating that the treatments induced negligible cytotoxic effects on normal RAW 264.7 macrophages.

In the second experiment (Figure 1B), LPS was used as the inducer to activate the RAW 264.7 cells. Treatment with $6 \mathrm{H} 2 \mathrm{MP}$ able to maintain the cell viability compared to $6 \mathrm{TG}$, where there is no significance difference in the cell viability percentage with diclofenac treated control group. Meanwhile 6TG treatment is unable to maintain the cell viability and further killing more cells. But this cannot be predicting early as the control results in this study showing there is no significant difference in the viability of cell between normal group, LPS- induced untreated group and LPS-induced diclofenac treated group.

The half maximal inhibitory concentration $\left(\mathrm{IC}_{50}\right)$ did not obtained within the ranges of doses 3.125-100 $\mu \mathrm{M}$ applied in this experiment. Based on these results, we employed both the drugs 6TG and 6H2MP used concentrations of 25 , 50 , and $100 \mu \mathrm{M}$, that did not adversely affect cell viability for experiments later.

\section{NO Production in LPS-induced RAW 264.7 Cells}

LPS-induced RAW 264.7 cells released high amounts of nitrite into the culture medium within 24 hours experiment (Figure 2). The treatment incubation of activated RAW 264.7 cells with $6 \mathrm{TG}$ and $6 \mathrm{H} 2 \mathrm{MP}$ reduce the NO production in concentration dependent manner at dose $50 \mu \mathrm{M}$ and 100 $\mu \mathrm{M}$, which is non-significance difference to LPS+diclofenac

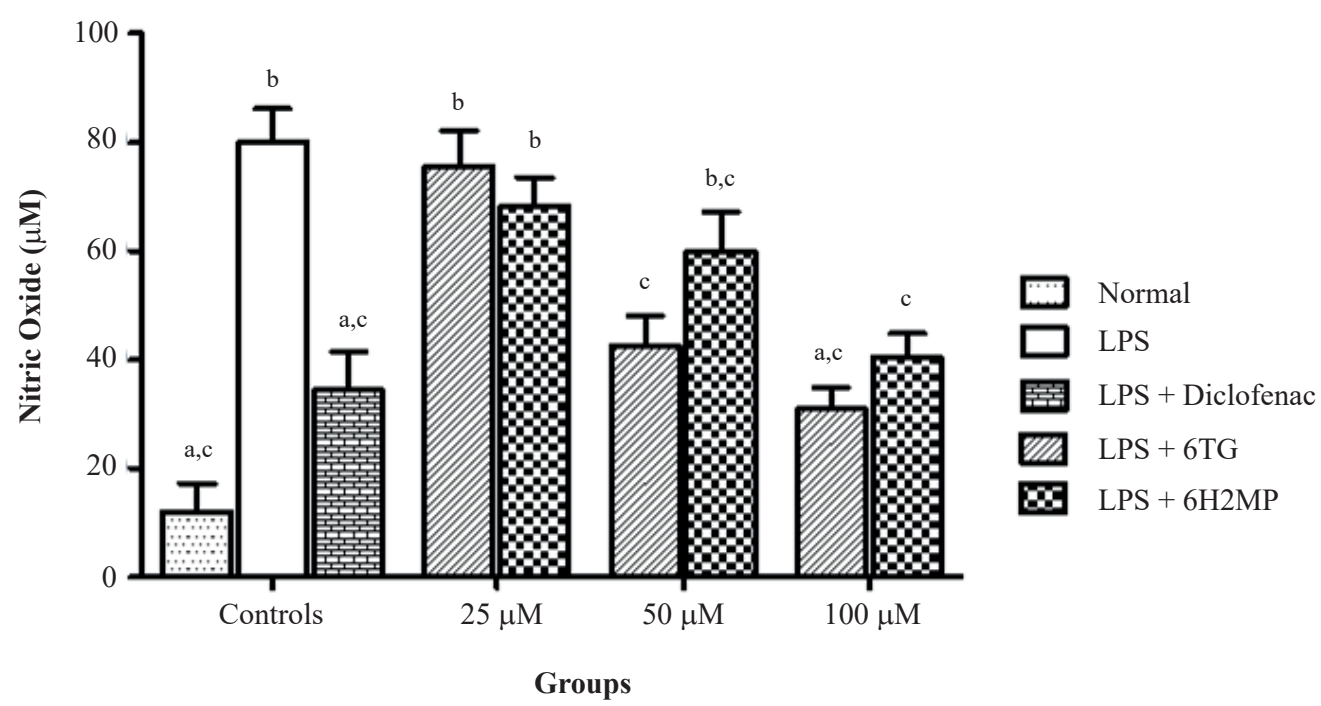

Figure 2. Quantitative data of NO in LPS-induced RAW 264.7 after being treated with different concentrations 25,50 and $100 \mu M$ of each 6TG and 6H2MP for 24 hours, respectively. Data were analysed using one-way ANOVA followed by Tukey HSD post hoc test and expressed as mean \pm SEM ( $\mathrm{n}=6)$. Values with different superscript letters differ significantly between groups $(p<0.05)$. 
treated group. Treatment with 6TG at dose $100 \mu \mathrm{M}$ attenuating the NO release from the cells with no significant different levels from the normal group.

Cell Viability Percentage on Non-induced and PMAinduced HIG-82 Cells for 24 Hours

The non-induced HIG-82 cells were incubated with varying concentrations of $6 \mathrm{TG}$ and $6 \mathrm{H} 2 \mathrm{MP}$ drugs separately 3.125$100 \mu \mathrm{M}$ for 24 hours to investigate the effects of both treatment on cell viability. Diclofenac has been used as positive control drug without activation of the cell. There were no-inducer has been used in experiment (Figure 3A) in order to test the toxic effects of the drug directly towards cell without any influence of activator. It was found out that there were no significant suppression of cell viability in all concentrations of the treatment drugs compared to normal group and also diclofenac-treated group.

In Figure 3B, cells were induced and activated with PMA $(0.1 \mu \mathrm{g} / \mathrm{mL})$. Diclofenac has been used as positive control drug with the activation of cells by PMA. Treatment with $6 \mathrm{TG}$ and $6 \mathrm{H} 2 \mathrm{MP}$ with doses of 3.125-100 $\mu \mathrm{M}$ for 24 hours did not produced any significance value of difference

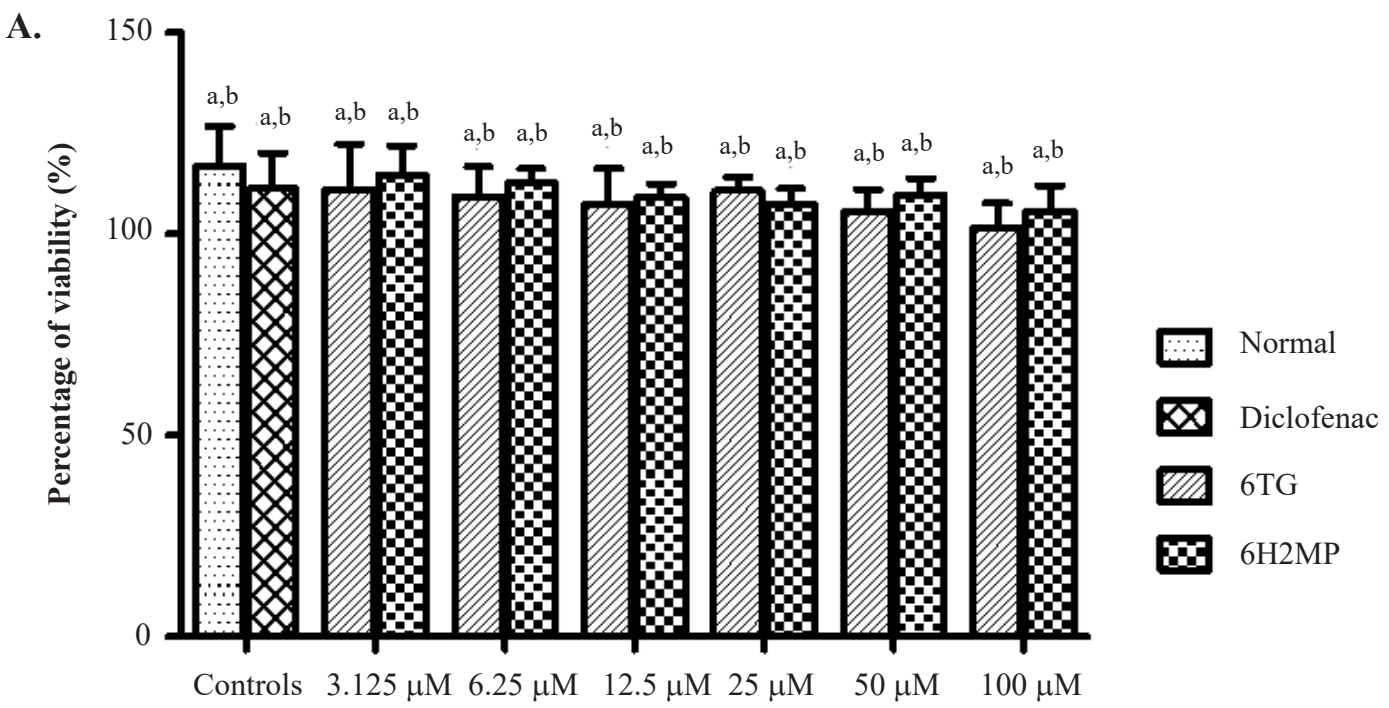

Groups

B.

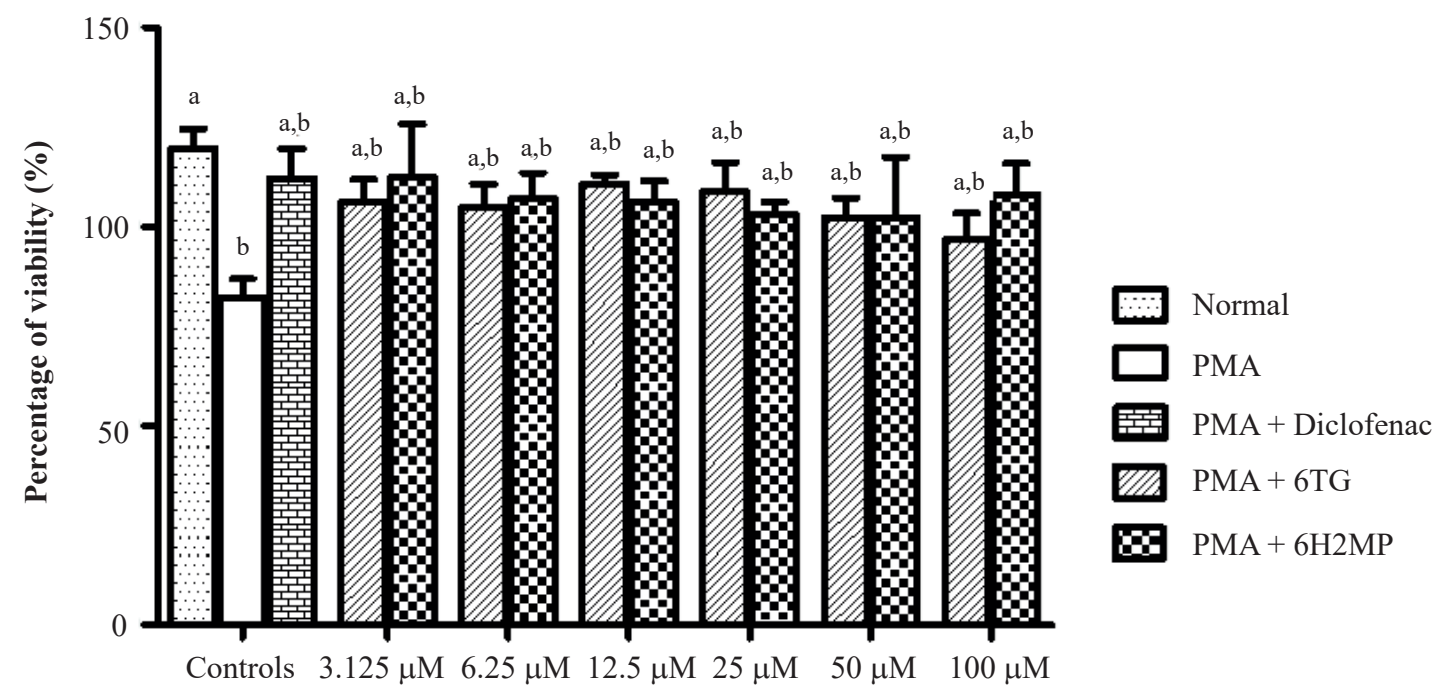

Groups

Figure 3. Percentage of viability of non-induced HIG-82 cells and PMA-induced HIG-82 cells treated with 6TG and 6H2MP for 24 hours. A: Percentage of viability of non-induced HIG-82 cells treated with 6TG and 6H2MP for 24 hours; B: Percentage of viability of PMA-induced HIG-82 cells treated with 6TG and 6H2MP for 24 hours. Data were analysed using one-way ANOVA followed by Tukey HSD post hoc test and expressed as mean $\pm \operatorname{SEM}(\mathrm{n}=6)$. Values with different superscript letters differ significantly between groups $(p<0.05)$. 
compared to control groups (normal group and diclofenac treated group). It showed the ability of these 2 drugs to retain the viability of cells when PMA was used to produce the inflammation towards HIG-82 cells colonies.

\section{Cell Viability Percentage on PMA-induced HIG-82 Cells for 48 and 72 hours}

In Figure 4A, the treatment 6TG 50 and $100 \mu \mathrm{M}$ and 6H2MP $(100 \mu \mathrm{M})$ in 48 hours exhibited a significance difference compared to control PMA+diclofenac group, thus showing toxicity effects and decrease the viability of cells. The $\mathrm{IC}_{50}$ for $6 \mathrm{TG}$ within 48 hours experiment is 10.73 , while for 6H2MP is 13.31 .

In Figure 4B, which was done in 72 hours, 6TG treatment on the PMA-induced HIG-82 cells was able to maintain the cell viability at the doses from $3.125 \mu \mathrm{M}$ to $25 \mu \mathrm{M}$. The viability of cells also maintains at the doses from $3.125 \mu \mathrm{M}$ to $50 \mu \mathrm{M}$ when treated with $6 \mathrm{H} 2 \mathrm{MP}$. Both treatment of $6 \mathrm{TG}$ and $6 \mathrm{H} 2 \mathrm{MP}$ at dose $25-100 \mu \mathrm{M}$ showing toxicity effects compared to normal group of cells. The $\mathrm{IC}_{50}$ for $6 \mathrm{TG}$ is 10.46 , while for $6 \mathrm{H} 2 \mathrm{MP}$ is 12.3 . From result, the percentage of viability of normal cells group was lower than
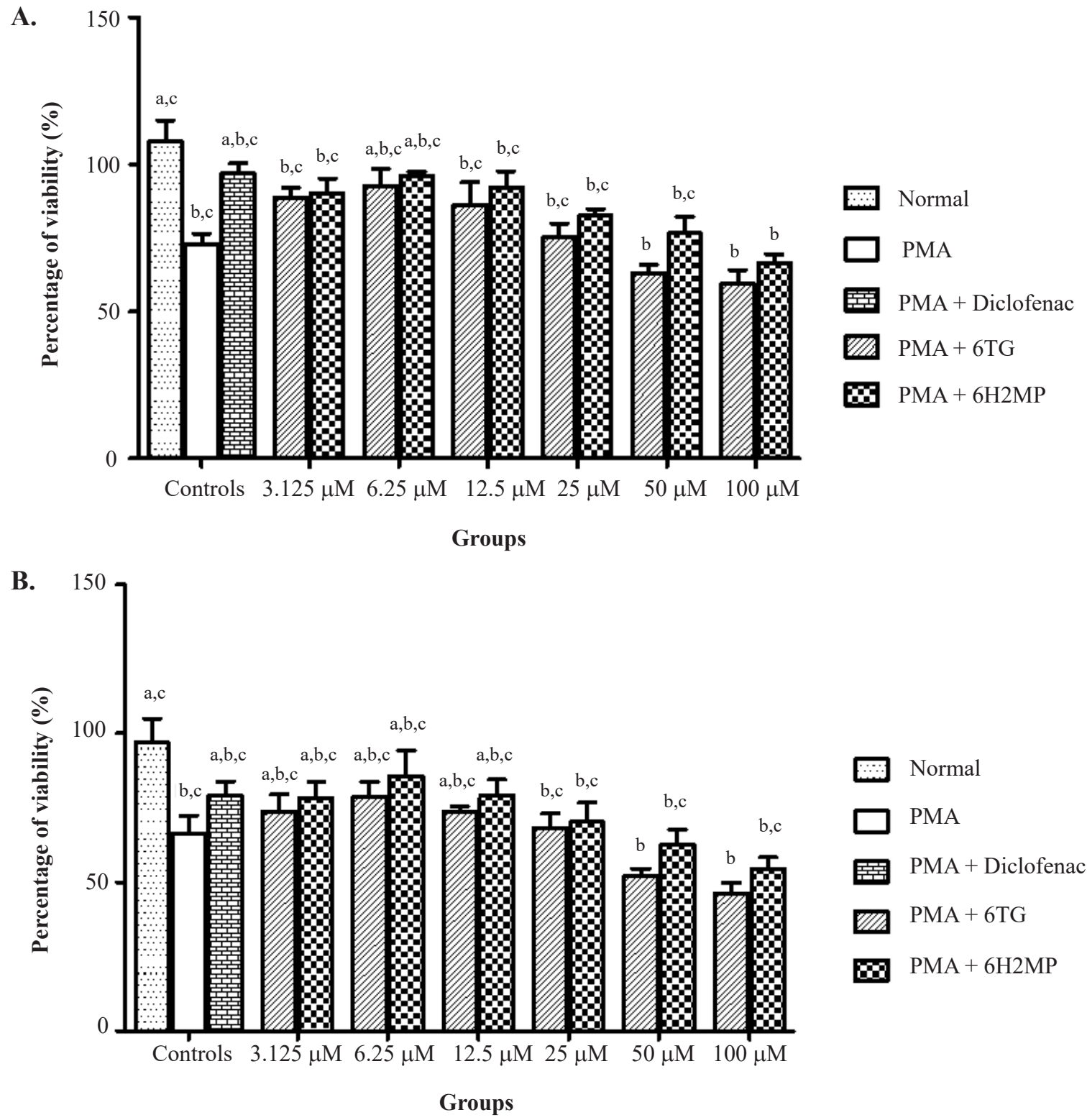

Figure 4. Percentage of viability of PMA-induced HIG-82 cells treated with 6TG and 6H2MP in 48 and 72 hours. A: Percentage of viability of PMA-induced HIG-82 cells treated with 6TG and 6H2MP in 48 hours; B: Percentage of viability of PMA-induced HIG-82 cells treated with 6TG and 6H2MP in 72 hours. Data were analysed using one-way ANOVA followed by Tukey HSD post hoc test and expressed as mean $\pm \operatorname{SEM}(\mathrm{n}=6)$. Values with different superscript letters differ significantly between groups $(p<0.05)$. 
$100 \%$. All groups of cells of controls and treatment doses also decrease in the cell percentage of viability into below than $100 \%$. The survival rate of the normal cells without any inducer or treatment decreased $9.7 \%$ from 24 hours treatment to 48 hours treatment. The rate further decreased in $10 \%$ from the 48 hours treatment to 72 hours treatment.

The overall results of activated HIG- 82 cells that treated with 6TG and $6 \mathrm{H} 2 \mathrm{MP}$, there is no significant suppression of cell viability were found at all concentrations 3.125-100 $\mu \mathrm{M}$ within $24 \mathrm{hr}$ treatment, showing that both drugs separately used can be the treatment against the cell cytotoxicity occurred in the cell cultured medium. Based on these results, we employed both of the drugs 6TG and $6 \mathrm{H} 2 \mathrm{MP}$ used concentrations of $25-100 \mu \mathrm{M}$ which apparently did not adversely affect cell viability for the subsequent experiments within 24 hours.

\section{NO Production in PMA-induced HIG-82 Cells}

NO levels in PMA-induced HIG-82 cells was decreasing when treated by $6 \mathrm{TG}$ and $6 \mathrm{H} 2 \mathrm{MP}$ at all doses; $25 \mu \mathrm{M}, 50$ $\mu \mathrm{M}$ and $100 \mu \mathrm{M}$ (Figure 5). At highest dose tested (100 $\mu \mathrm{M})$, it shows the significance difference of result between treatments and PMA-induced untreated group, revealing the ability of 6TG and 6H2MP to fully inhibit NO production in this studied culture medium.

\section{PGE2 Biosynthesis in PMA-induced HIG-82 Cells}

The results of the PGE2 assay revealed that $6 \mathrm{TG}$ and $6 \mathrm{H} 2 \mathrm{MP}$ at all concentrations tested are able to inhibit PGE2 release from PMA-induced HIG-82 cells. The treatment with 6TG inhibit PGE2 at dose $50 \mu \mathrm{M}$ and $100 \mu \mathrm{M}$ while $6 \mathrm{H} 2 \mathrm{MP}$ was able to inhibit PGE2 levels at dose $100 \mu \mathrm{M}$, which was based on the non-significance difference in results analysis with diclofenac-treated control group (PMA+diclofenac). In controls groups of experiment, HIG-82 cells that were induced with PMA showed a 7.8-fold increase in PGE2 secretion compared to non-induced cells (normal group) (Figure 6).

\section{Inflammatory Cytokines (TNF- $\alpha$, IL-1 $\beta$ and IL-6) Levels in PMA-induced HIG-82 Cells}

The pro-inflammatory cytokine activity concentrations of TNF- $\alpha$, IL-1 $\beta$ and IL-6 indicates the anti-inflammatory activity in the PMA-induced HIG-82 cells were illustrated in Figure 7 (A, B and C), respectively. In TNF- $\alpha$ analysis, results showed that treatments with $6 \mathrm{TG}$ and $6 \mathrm{H} 2 \mathrm{MP}$ at all doses 25-100 $\mu \mathrm{M}$ were able to decrease TNF- $\alpha$ levels in dose dependent effects. But there was no significant difference of all the TNF- $\alpha$ concentration levels in sample groups compared to normal group, indicates the treatment dose does not produce enough effect for the activated cells to turn into normal levels. Meanwhile, 6TG treatment was effective to decrease IL-1 $\beta$ levels in the activated HIG-82 cells at all doses (25-100) $\mu \mathrm{M}$, with no significant difference in statistical analysis compared to PMA-treated control group (PMA+diclofenac). The IL-6 levels of activated HIG-82 cells also decreased in concentration at all doses 25-100 $\mu \mathrm{M}$ when treated with 6TG and 6H2MP, with no significance difference compared to PMA-treated control group (PMA+diclofenac) and normal group.

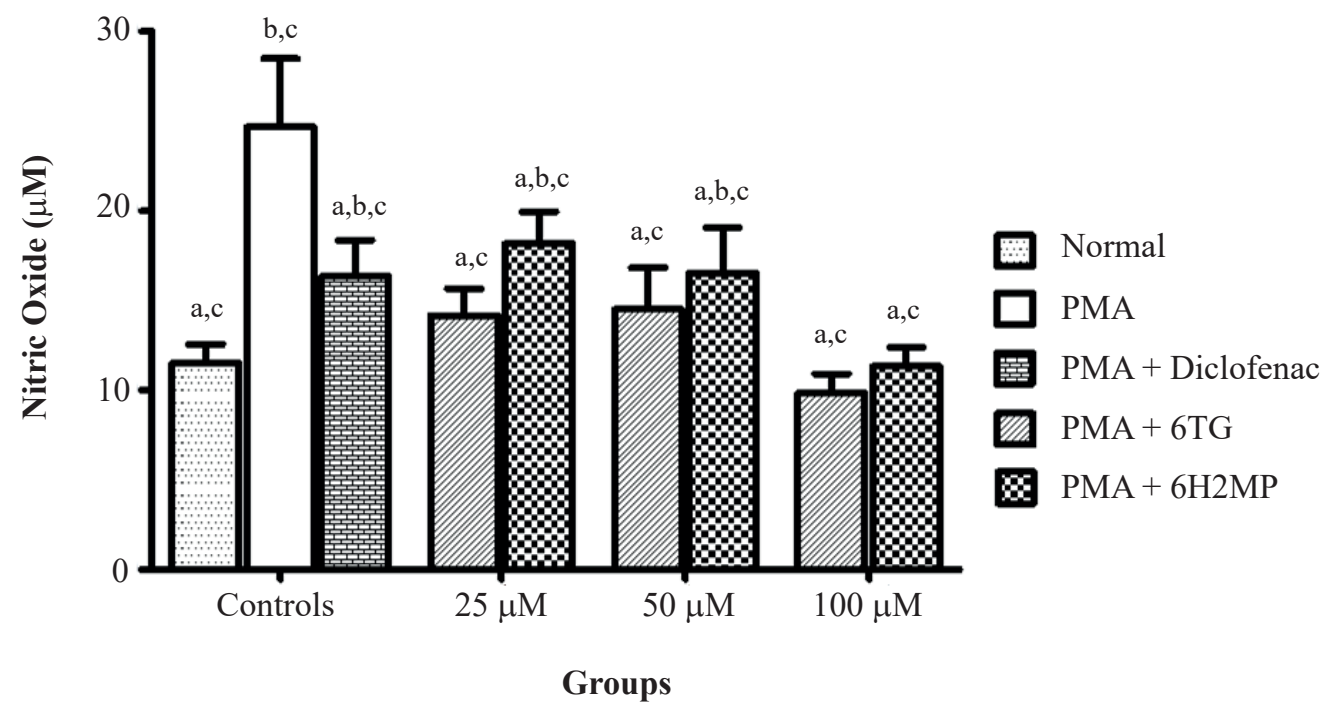

Figure 5. Quantitative data of Nitric Oxide in PMA-induced HIG-82 cells after being treated with different concentrations 25, 50 and $100 \mu \mathrm{M}$ of each 6TG and 6H2MP for 24 hours, respectively. Data were analysed using one-way ANOVA followed by Tukey HSD post hoc test and expressed as mean $\pm \operatorname{SEM}(\mathrm{n}=6)$. Values with different superscript letters differ significantly between groups $(p<0.05)$. 


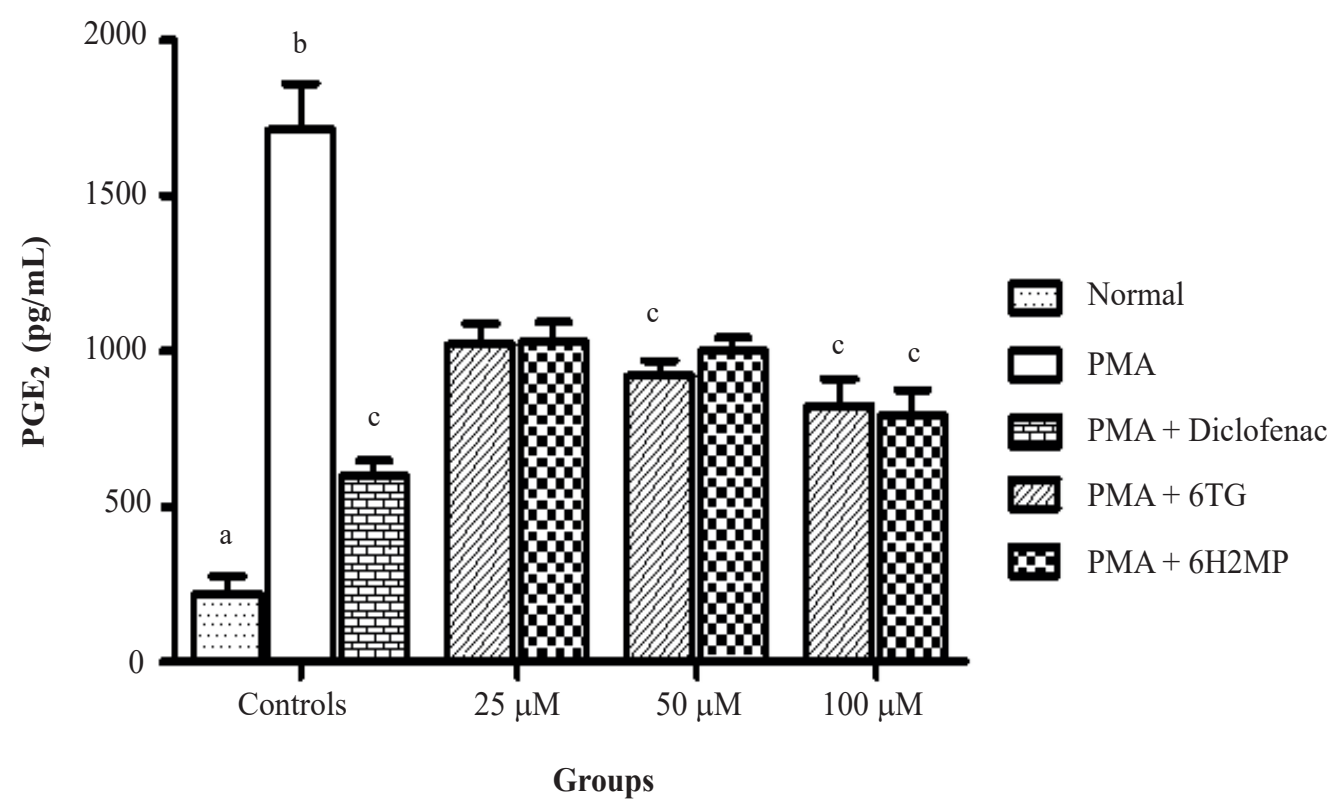

Figure 6. Quantitative data of PGE2 levels in PMA-induced HIG-82 cells after being treated with different concentrations 25, 50 and $100 \mu \mathrm{M}$ of each 6TG and 6H2MP for 24 hours, respectively. Data were analysed using one-way ANOVA followed by Tukey HSD post hoc test and expressed as mean $\pm \operatorname{SEM}(\mathrm{n}=6)$. Values with different superscript letters differ significantly between groups $(p<0.05)$.

\section{Discussion}

This study constantly demonstrated that $6 \mathrm{TG}$ and $6 \mathrm{H} 2 \mathrm{MP}$ treatment on normal RAW 264.7 macrophages via MTT assay for 24 hours did not produce any significant cytotoxic effects in comparison with our control drug, diclofenac. When RAW 264.7 macrophages cells activated with LPS, apoptosis was triggered, and the cytotoxicity of the cells occurred. Treatment with $6 \mathrm{H} 2 \mathrm{MP}$ also showed apoptosis in the activated cells, but less effect compared to $6 \mathrm{TG}$ at the same doses. The reactions of cell lines to these two drugs may be due to the polymorphic levels of enzymes expression within the cell which associated with drugs metabolism. The two main enzymes are thiopurine methyl transferase (TPMT) and hypoxanthine guanine phosphoribosyl transferase (HGPRT), which plays main part in breaking down (metabolizing) thiopurine drugs into inactive, nontoxic compounds. TPMT enzyme respectively forms the anti-metabolic products and generates the pro-apoptotic metabolites during metabolism process.(9) Both activation of $6 \mathrm{TG}$ and $6 \mathrm{H} 2 \mathrm{MP}$ is catalyzed by hypoxanthine-guanine phosphoribosyl transferase (HGPRT), following by the multi-step transformation to thioguanine nucleotides (TGNs) that further incorporated into DNA or RNA and inhibit the de novo purine synthesis (DNPS). The TPMT enzyme is responsible for methylation $6 \mathrm{TG}$ and $6 \mathrm{H} 2 \mathrm{MP}$ into different methylated metabolites, which are methylthioguanosine monophosphate (meTGMP) and methylthioinosine monophosphate (meTIMP), respectively.(10)

In inflammation, macrophages will produce cytokines/ chemokines and various inflammatory mediators, including NO. Reduction in the production of inflammatory mediators in the macrophages maybe beneficial in the treatment of many inflammatory diseases.(11) NO occupy pro-apoptotic properties in macrophages, with high levels induces cell cycle arrest, apoptosis and senescence.(12) The inducible isoform of Nitric Oxide Synthase (iNOS) suppression in LPS-stimulated RAW 264.7 cells are important criteria to inhibit NO production.(13) LPS has been shown can induce iNOS expression and production of NO by a variety of cells including murine macrophage RAW264.7 cells.(14) There are reports in RA studies on increased endogenous NO synthesis and this evidence proposed that NO mediates $\mathrm{T}$ cell dysfunction in autoimmune disease. Therefore, $\mathrm{NO}$ inhibition in LPS-stimulated RAW 264.7 cells is one of the potential approaches to screen the various anti-inflammatory drugs.(13)

The control treatment drug in this study, diclofenac significantly inhibited NO production induced by LPS in RAW 264.7 macrophages. This is similar to the previous study published (15) and consistent with other studies in which diclofenac and aspirin-like NSAIDs inhibit NO production in diverse cultured cell types (16), even though the precise mechanism of iNOS expression by diclofenac has not yet been fully understand. In the presence of endotoxin 

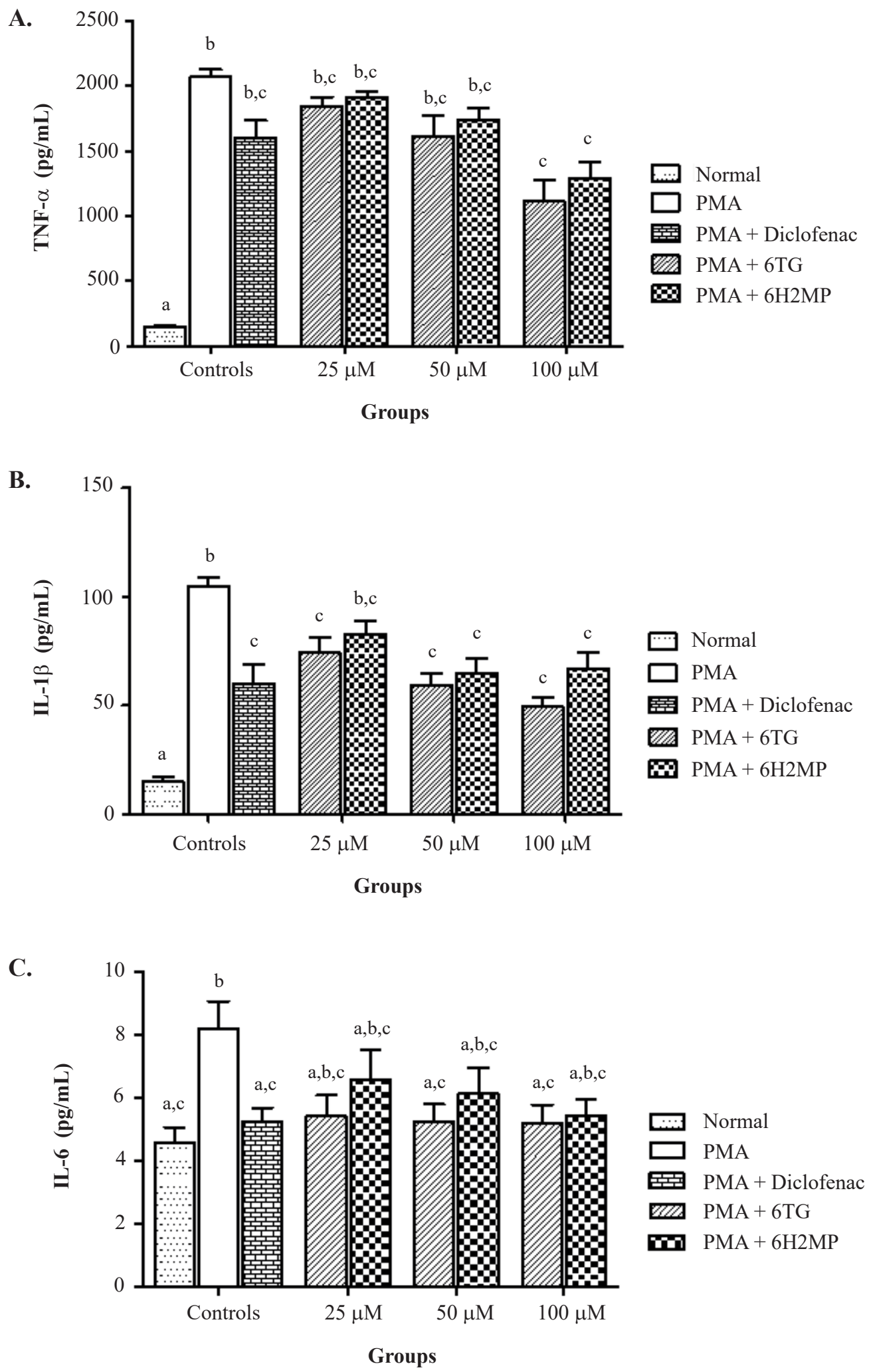

Figure 7. The inhibitory effects between 6TG and 6H2MP treatment on TNF- $\alpha$, IL-1ß, and IL-6 level production towards PMAinduced HIG-82 cells. A: The inhibitory effects between 6TG and 6H2MP treatment on TNF- $\alpha$ level production towards PMA-induced HIG-82 cells; B: The inhibitory effects between $6 \mathrm{TG}$ and $6 \mathrm{H} 2 \mathrm{MP}$ treatment on IL-1 $\beta$ level production towards PMA-induced HIG-82 cells; C: The inhibitory effects between 6TG and 6H2MP treatment on IL-6 level production towards PMA-induced HIG-82 cells. Data were analysed using one-way ANOVA followed by Tukey HSD post hoc test and expressed as mean \pm SEM ( $n=6$ ). Values with different superscript letters differ significantly between groups $(p<0.05)$. 
and cytokines in an inflammatory setting, macrophage expressed the inducible iNOS. The expression of iNOS is high in macrophages that are activated with LPS. LPS activate macrophage by Toll-like receptor 4 (TLR4) and stimulates mitogen-activated protein (MAP) kinase/JNK signalling cascades, leading to the NF-KB activation.(17) It has been suggested that the anti-inflammatory effects of diclofenac may exert by inhibiting the iNOS gene expression at the transcriptional level through NF-kB activity suppression. Diclofenac is a nonsteroidal anti-inflammatory analgesic which is widely used in arthritic-type diseases, for acute pain, and during the post-operative period. It also can induce other action mechanisms that leads to its analgesic properties but its regulation for long durations of time is not suggested due to adverse gastrointestinal effects.(18)

The results in this study also demonstrated that studied drugs $6 \mathrm{TG}$ and $6 \mathrm{H} 2 \mathrm{MP}$ were significantly decreased the accumulation of NO in LPS-stimulated RAW 264.7 cells with concentration dependent manner. 6TG compound effectively inhibited the production of $\mathrm{NO}$ compared to $6 \mathrm{H} 2 \mathrm{MP}$ in the same dose and might be important in inflammatory diseases prevention mediated by enormous generation of NO. High iNOS activity may cause increased in NO production and leads to tissue damage. Exposure of Thiopurine family of drugs influence macrophage functions by inhibiting the Rac1/JNK signalling, leads to decrease in iNOS expression following by decreased the NO production. The treatment with 6MP resulted in Rac1-JNK-cJun-dependent iNOS expression inhibition in activated macrophages.(19) The 6MP thoroughly restrain Rac1 activity in $\mathrm{CD}^{+}{ }^{+} \mathrm{T}$-cell differentiation and efficiently attenuate activation of JNK-mediated signaling in macrophages, thus inhibit the interaction and activation with antigen presenting cells such as macrophages. Inactivation or activation of Rac1 by affiliate with guanosine diphosphate (GDP) and guanosine triphosphate (GTP). It involves in many cellular downstream cellular activities central to normal cell physiology such as cellular adhesions, cell proliferation, migration and invasion, reactive oxygen species (ROS) production, apoptosis, and inflammatory responses. The role in cancer of Rac1 may provide the proliferative and invasive characteristic of fibroblast-like synoviocytes that have been isolated from patients involved with RA. Thus, the chemical inhibition and Rac1 depletion might counteract the aggressive tumor-like features of fibroblast-like synoviocytes. The suppression of Rac1 activity might help to lessen the clinical symptoms of inflammatory arthritis.(20)

In this study, the cytotoxicity and anti-inflammatory properties of $6 \mathrm{TG}$ and $6 \mathrm{H} 2 \mathrm{MP}$ were going further into HIG-
82 rabbit synovial fibroblast cells, revealing the treatment of 6TG and 6H2MP did not inhibit synoviocyte viability in 24 hours via MTT assay. The observation is similar with data obtained on previous study of RAW 264.7 macrophages cells. This means the treatment with either 2 drugs did not produce any toxicity towards non-PMA induced HIG-82 cells within 24 hours. The result produces same manner which in PMA-induced HIG-82 cells within 24 hours, where both $6 \mathrm{TG}$ and $6 \mathrm{H} 2 \mathrm{MP}$ drugs also did not produce toxicity. The cytotoxicity occurs apparently for 48 hours and 72 hours treatment, where $\mathrm{IC}_{50}$ for $6 \mathrm{TG}$ is lower than $6 \mathrm{H} 2 \mathrm{MP}$ in both experiments. The $\mathrm{IC}_{50}$ for $6 \mathrm{TG}$ within 48 hours experiment is 10.73 , while for $6 \mathrm{H} 2 \mathrm{MP}$ is 13.31 . The $\mathrm{IC}_{50}$ in 72 hours experiment for $6 \mathrm{TG}$ is 10.46 , while for $6 \mathrm{H} 2 \mathrm{MP}$ is 12.3 . This may prove that the direct metabolism of 6TG to 6-TGNs (6-thioguanine nucleotides) prevents the enzymatic variability due to genetic polymorphism and refrain the intolerance of azathioprine inducer. This allow them to produce cytotoxicity towards cell in lower dose compared to $6 \mathrm{H} 2 \mathrm{MP}$, thus observing of 6-TGNs may contribute to treatment optimization.

This study shows drug $6 \mathrm{H} 2 \mathrm{MP}$ produces a significant dose dependent suppression of NO production by synovial cells and proved that PMA $0.1(\mu \mathrm{g} / \mathrm{mL})$ is able to induce higher NO synthesis. This is similar to other study which stated that synovial fibroblast have the potential to synthesize NO.(21) Concentrations of NO and nitrite in serum and the synovial tissues of RA patients are significantly higher compared to healthy control.(22) NO act as a mediator that controls cell activity at the inflammatory sites such as production of cytokines, signal transduction, mitochondrial activity and apoptosis.(23) Caspase- 3 is a cysteine protease and a central effector of many apoptotic pathways allocated in mitochondrial intermembrane space and cytoplasm. In resting cells, the enzyme activity is inhibiting by S-nitrosylation process of caspase-3 at the active site of cysteine. Increased NO level may inhibit the synovial fibroblasts apoptotic cell death by restricting the activation caspase- 3 by nitrosylation of thiol group, and this action leads to RA pathogenesis.(24)

The activated HIG-82 cells by PMA secrete prostaglandin E2 (PGE2) into their culture medium. (2) Result showed that both drugs, 6TG and 6H2MP are able to reduce PGE2 production, which is correlates with their ability to inhibit the NO production at dose $100 \mu \mathrm{M}$. Among arthritis patients, the increase of PGE2 is likely to be from synovial cells and macrophages. NO may activate cyclooxygenase and increase the level of prostaglandin, but currently there is no systematic justification of the cross- 
talks mechanism between NO and COX-2 and PGE2 in the normal or tumour cell co-cultures at.(25)

Results shows that levels of TNF- $\alpha$, IL- $1 \beta$ and IL- 6 which are key agents in the process of inflammation were reduced following the increasing dose, indicating that $6 \mathrm{TG}$ and 6H2MP drugs might influenced the selected leukocyte populations recruitment and activation.(16) Leukocytes migration to the inflamed areas is regulated by a caspase of reaction involving rolling leukocytes on the endothelium, leukocytes activation and adhesion to endothelial ligands, transendothelial migration into the surrounding tissue, and the movement of inflammatory cells through the tissue in reactions to chemokine gradients.(26) Diclofenac used as the positive control treatment was able to decrease the TNF- $\alpha$ and IL- 6 level, this also confirmed by other study. (27) Hence it also decreases the level of IL-1 $\beta$ in this study, which also could increase Rac1 action.(28)

The 6-Mercaptopurine is powerful to decrease the PMA-induced expression of assorted pro-inflammatory cytokines in human NCI-H292 mucoepidermoid carcinoma and mouse lung epithelial MLE-12 cells.(10) It decreases Rac1 activity in MLE-12 cells, thus this might be the same activity pathway involved in this study by using PMAinduced synovial fibroblast cells, HIG-82. 6-MP treatment on chronic rhinosinusitis (CRS) with nasal polyps (NPs) also exhibit lower expression of TNF- $\alpha$ in mRNA level.(28)

The 6TG significantly is effective to decrease the IL-6 generation in colon.(29) The immunosuppressive action of $6 \mathrm{TG}$ may be associated to the acute inhibition of cytokine stimulation.(30) Biochemically, thioguanine (including 6TG) propense to incorporate during DNA synthesis impeding cell propagation hence lessening the availibility of macrophages which might concurrently reduce TNF- $\alpha$. A study has demonstrated that treatment of 6TG together with particular drug significantly reduce the optimum dose needed to induce anti-TNF- $\alpha$ capability.(31) Mechanism of $6-\mathrm{TG}$ on TNF- $\alpha$ production appear to be dependent on the host of entity thus targeting the transcriptional process of DNA explain much of the capability of the compound itself as immunosuppressant. The 6-thioguanine nucleotides were assumed to promote apoptosis of activated $\mathrm{T}$ lymphocytes and further leads to the overactive immune defence mechanisms suppression.(32)

As depicted by 6TG, 6H2MP may induce similar mechanism of action on TNF- $\alpha$ as stated previously, alleviating its presence. Its capability in suppressing inflammation was meticulously associated with reducing oxidative stress involving myeloperoxidase (MPO).(33) However, inverse reaction between the availability of
TNF- $\alpha$ and MPO where its production was significantly reduced with exposure to TNF- $\alpha$. (34) This outcome although not directly reflect the observation as in our study, yet the association exist as both TNF- $\alpha$ and MPO are mainly present in RA disease.(35) Furthermore, NO displays the capability in regulating the activity of myeloperoxidase in inflammatory condition.(36) The 6H2MP on the other hand reduce the level of MPO (34) and the present of NO was decreased as acquired hence justify that the action of this compound was on the integrity of the cells rather than literally involve in regulating the presence of TNF- $\alpha$.

\section{Conclusion}

The results upon LPS-induced RAW 264.7 macrophages demonstrated that $6 \mathrm{H} 2 \mathrm{MP}$ and $6 \mathrm{TG}$ are able to suppress the production of NO in vitro. Further studied in PMAinduced HIG-82 synovial fibroblast cells shows that $6 \mathrm{H} 2 \mathrm{MP}$ and $6 \mathrm{TG}$ also suppress the release of NO, PGE2, and inflammatory cytokines (IL-1, IL1 $\beta$ and IL-6), in vitro. $6 \mathrm{TG}$ is more effective to reduce inflammatory reactions compared to $6 \mathrm{H} 2 \mathrm{MP}$. It shows suppression in lower dose compared to 6H2MP in all experiments except in PGE2. The inhibition of TNF $\alpha$, IL1 $\beta$ and NO is an important mechanism by which 6TG and 6H2MP may affect pain and articular inflammation.

\section{Authors Contribution}

YYK, SFMT, and MNH were involved in the study conception. NSN and ZNMZ did the data acquisition, meanwhile NSN, YYK, SFMT, and ZNMZ analyzed the data. NSN, SFMT, MNH interpreted the data. NSN and $\mathrm{MNH}$ did the table design. All authors took parts in giving critical revision of the manuscript.

\section{References}

1. Lee SC, Kwon YW, Park JY, Park SY, Lee JH, Park SD. (2017). Antioxidant and anti-inflammatory effects of herbal formula SC-E3 in lipopolysaccharide-stimulated RAW 264.7 macrophages. eCAM. 2017; 2017: 1725246. doi: 10.1155/2017/1725246.

2. Chen J, Er HM, Mohamed SM, Chen YS. In vitro anti-inflammatory activity of fractionated Euphorbia hirta aqueous extract on rabbit synovial fibroblasts. Biomed J. 2015; 38: 301-6.

3. Petit E, Langouet S, Akhdar H, Nicolas-Nicolaz C, Guillouzo A, Morel F. Differential toxic effects of azathioprine, 6-mercaptopurine and 6-thioguanine on human hepatocytes. Toxicol in vitro. 2008; 22: $632-42$ 
4. Karim H, Hashemi J, Larsson C, Moshfegh A, Fotoohi AK, Albertioni F. The pattern of gene expression and gene dose profiles of 6-Mercaptopurine-and 6-Thioguanine-resistant human leukemia cells. Biochem Biophys Res Commun. 2011; 411: 156-61.

5. Deshpande AR, Abreu MT. Optimizing therapy with 6-mercaptopurine and azathioprine: To measure or not to measure? Therap Adv Gastroenterol. 2010; 3: 275-9.

6. Kim I, Choi YS, Song JH, Choi EA, Park S, Lee EJ, et al. A drugrepositioning screen for primary pancreatic ductal adenocarcinoma cells identifies 6-thioguanine as an effective therapeutic agent for TPMT-low cancer cells. Mol Oncol. 2018; 12: 1526-39.

7. Shin JH, Ryu JH, Kang MJ, Hwang CR, Han J, Kang D. Shortterm heating reduces the anti-inflammatory effects of fresh raw garlic extracts on the LPS-induced production of NO and proinflammatory cytokines by downregulating allicin activity in RAW 264.7 macrophages. Food Chem. Toxicol. 2013; 58: 545-51.

8. Chiong HS, Yong YK, Ahmad Z, Sulaiman MR, Zakaria ZA, Yuen $\mathrm{KH}$, et al. (2013). Cytoprotective and enhanced anti-inflammatory activities of liposomal piroxicam formulation in lipopolysaccharidestimulated RAW 264.7 macrophages. Int J Nanomedicine. 2013; 8, 1245-55.

9. Seidman EG. Clinical use and practical application of TPMT enzyme and 6-mercaptopurine metabolite monitoring in IBD. Rev Gastroenterol Disord. 2003; 3 (Suppl 1): S30-8.

10. Kurakula K, Hamers AA, van Loenen P, de Vries CJ. 6-Mercaptopurine reduces cytokine and Muc5ac expression involving inhibition of NFKB activation in airway epithelial cells. Respir Res. 2015; 16: 73. doi: 10.1186/s12931-015-0236-0.

11. Murthuza S, Manjunatha BK. In vitro and in vivo evaluation of antiinflammatory potency of Mesua ferrea, Saraca asoca, Viscum album \& Anthocephalus cadamba in murine macrophages raw 264.7 cell lines and Wistar albino rats. Beni-Suef Univ J Basic Appl Sci. 2018; 7: 719-23

12. Romanowicz GE, He W, Nielsen M, Frost MC. Novel device for continuous spatial control and temporal delivery of nitric oxide for in vitro cell culture. Redox Biol. 2013; 1: 332-9.

13. Joo T, Sowndhararajan K, Hong S, Lee J, Park SY, Kim S, et al. Inhibition of nitric oxide production in LPS-stimulated RAW 264.7 cells by stem bark of Ulmus pumila L. Saudi J Biol Sci. 2014; 21 : 427-35.

14. Sosroseno W, Bird PS, Seymour GJ. Nitric oxide production by a murine macrophage cell line (RAW264.7 cells) stimulated with Aggregatibacter actinomycetemcomitans surface-associated material. Anaerobe. 2011; 17: 246-51.

15. Villalonga N, David M, Bielańska J, González T, Parra D, Soler C, et al. Immunomodulatory effects of diclofenac in leukocytes through the targeting of Kv1. 3 voltage-dependent potassium channels. Biochem Pharmacol. 2010; 80: 858-66.

16. Bombardo M, Malagola E, Chen R, Rudnicka A, Graf R, Sonda S. Ibuprofen and diclofenac treatments reduce proliferation of pancreatic acinar cells upon inflammatory injury and mitogenic stimulation. Br J Pharmacol. 2018; 175: 335-47.

17. Kaminska B. MAPK signalling pathways as molecular targets for antiinflammatory therapy - From molecular mechanisms to therapeutic benefits. Biochim Biophys Acta Proteins Proteom. 2005; 1754: 25362.

18. Al-Nimer MSM, Ali EA. Dual effects of interaction between meloxicam, diclofenac sodium or tramadol and nitrogen species radicals: In vitro comparative study. Int J Pharmacol. 2009; 5: 86-9.

19. Marinković G, Hamers AA, de Vries CJ, de Waard V. 6-Mercaptopurine reduces macrophage activation and gut epithelium proliferation through inhibition of GTPase Rac1. Inflamm Bowel Dis. 2014; 20 1487-95.

20. Marei H, Malliri A. Rac1 in human diseases: The therapeutic potential of targeting Rac1 signaling regulatory mechanisms. Small GTPases. 2017; 8: 139-63.

21. Stefanovic-Racic M, Stadler J, Georgescu HI, Evans CH. Nitric oxide and energy production in articular chondrocytes. J Cell Physiol. 1994; 159: 274-80.

22. Dey P, Panga V, Raghunathan S. A cytokine signalling network for the regulation of inducible nitric oxide synthase expression in rheumatoid arthritis. PLoS One. 2016; 11: e0161306. doi: 10.1371/ journal.pone.0161306.

23. Casnici C, Lattuada D, Tonna N, Crotta K, Storini C, Bianco F, et al. Optimized "in vitro" culture conditions for human rheumatoid arthritis synovial fibroblasts. Mediators Inflamm. 2014; 2014: 702057. doi: 10.1155/2014/702057.

24. Kumar DA, Settu K, Raju KVN, Kumanan K, Manohar BM, Puvanakrishnan R. Inhibition of nitric oxide and caspase-3 mediated apoptosis by a tetrapeptide derivative (PEP1261) in cultured synovial fibroblasts from collagen-induced arthritis. Mol Cell Biochem. 2006; 282: 125-39.

25. Paduch R, Kandefer-Szerszeń M. Nitric oxide (NO) and cyclooxygenase-2 (COX-2) cross-talk in co-cultures of tumor spheroids with normal cells. Cancer Microenviron. 2011; 4: 187-98.

26. Palmer G, Gabay C, Imhof BA. Leukocyte migration to rheumatoid joints: enzymes take over. Arthritis Rheumatol. 2006; 54: $2707-$ 10.

27. Gallelli L, Galasso O, Falcone D, Southworth S, Greco M, Ventura $\mathrm{V}$, et al. The effects of nonsteroidal anti-inflammatory drugs on clinical outcomes, synovial fluid cytokine concentration and signal transduction pathways in knee osteoarthritis. A randomized open label trial. Osteoarthr Cartil. 2013; 21: 1400-8.

28. Yeo NK, Park WJ, Eom DW, Oh MY, Lee JH. Effects of azathioprine and its metabolites on inflammatory cytokines in human nasal polyp organ cultures. Int Forum Allergy Rhinol. 2019; 9: 648-55.

29. Kverka M, Rossmann P, Tlaskalova-Hogenova H, Klimesova $\mathrm{K}$, Jharap B, de Boer NK, et al. Safety and efficacy of the immunosuppressive agent 6-tioguanine in murine model of acute and chronic colitis. BMC Gastroenterol. 2011; 11: 1-9.

30. Tan YY, Epstein LB, Armstrong RD. In vitro evaluation of 6 -thioguanine and $\alpha$-interferon as a therapeutic combination in HL60 and natural killer cells. Cancer Res. 1989; 49: 4431-4.

31. Yarur AJ, Abreu MT, Deshpande AR, Kerman DH, Sussman DA. Therapeutic drug monitoring in patients with inflammatory bowel disease. World J Gastroenterol. 2014; 20: 3475-84.

32. Shivashankara AR, Rao S, George T, Abraham S, Colin MD, Palatty PL, et al. Chapter 15: Tea (Camellia sinensis L. Kuntze) as hepatoprotective agent: a revisit. In: Dietary Interventions in Liver Disease. Cambride: Academic Press; 2019. p. 183-92.

33. Tidén AK, Sjögren T, Svensson M, Bernlind A, Senthilmohan R, Auchère F, Lundquist S. 2-thioxanthines are mechanism-based inactivators of myeloperoxidase that block oxidative stress during inflammation. J Biol Chem. 2011; 286: 37578-89.

34. Hachiya M, Osawa Y, Akashi M. Role of TNF- $\alpha$ in regulation of myeloperoxidase expression in irradiated HL60 promyelocytic cells. Biochim Biophys Acta Mol Cell Res. 2000; 1495: 237-49.

35. Matsuno H, Yudoh K, Katayama R, Nakazawa F, Uzuki M, Sawai T, et al. The role of TNF- $\alpha$ in the pathogenesis of inflammation and joint destruction in rheumatoid arthritis (RA): a study using a human RA/SCID mouse chimera. Rheumatology. 2002; 41: 329-37.

36. Abu-Soud HM, Hazen SL. Nitric oxide modulates the catalytic activity of myeloperoxidase. J Biol Chem. 2000; 275: 5425-30. 